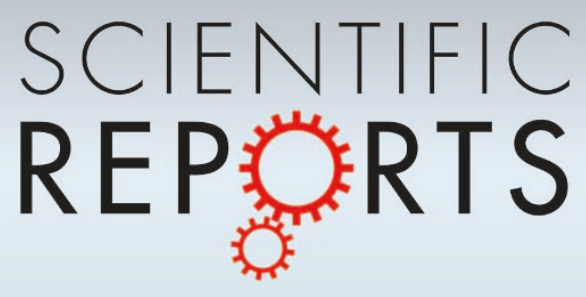

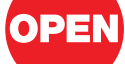

SUBJECT AREAS:

TARGET VALIDATION

DNA

ASSAY SYSTEMS

PCR-BASED TECHNIQUES

Received

6 November 2012

Accepted

19 November 2012

Published

11 December 2012

Correspondence and requests for materials should be addressed to

Z.T. (tangzhuo@cib. ac.cn) or Y.D.

(dengyun2000@ hotmail.com)

\section{DNA based identification of medicinal materials in Chinese patent medicines}

\author{
Rong Chen ', Juan Dong' ${ }^{1}$ Xin Cui ', Wei Wang ${ }^{2}$, Afshan Yasmeen ', Yun Deng ${ }^{2}$, Xiaomao Zeng ${ }^{3}$ \\ \& Zhuo Tang'
}

${ }^{1}$ Natural Products Research Center, Chengdu Institution of Biology, Chinese Academy of Science, Chengdu, P. R. China, ${ }^{2}$ State Key Laboratory Breeding Base of Systematic Reseach, Development and Utilization of Chinese Medicine Resource, Chengdu University of TCM, Chengdu, P. R. China, ${ }^{3}$ Department of Herpetology, Chengdu Institution of Biology, Chinese Academy of Science, Chengdu, P. R. China.

Chinese patent medicines (CPM) are highly processed and easy to use Traditional Chinese Medicine (TCM). The market for CPM in China alone is tens of billions US dollars annually and some of the CPM are also used as dietary supplements for health augmentation in the western countries. But concerns continue to be raised about the legality, safety and efficacy of many popular CPM. Here we report a pioneer work of applying molecular biotechnology to the identification of CPM, particularly well refined oral liquids and injections. What's more, this PCR based method can also be developed to an easy to use and cost-effective visual chip by taking advantage of G-quadruplex based Hybridization Chain Reaction. This study demonstrates that DNA identification of specific Medicinal materials is an efficient and cost-effective way to audit highly processed $\mathrm{CPM}$ and will assist in monitoring their quality and legality.

(Ko raditional Chinese Medicine (TCM) has been used for health care in China and other oriental countries like Korea and Japan for thousands of years. It also enjoys a growing popularity both in eastern and western countries nowadays rather than abandoned by the highly developed science and technology. According to different processing technology, TCM can be divided into Chinese medicinal raw materials, prepared slices and Chinese patent medicines (CPM). CPM are highly processed drugs which consist of several kinds of or even dozens kinds of plants or animals. Compared to the other two types of TCM, CPM are more convenient to use for both doctors and patients. The market for CPM in China alone is tens of billions US dollars annually and since the therapeutic benefits of some CPM have been validated scientifically, they are more widely used all over the world. For example, after validation studies, Diao Xin Xue Kang capsule has already been licensed for sale in EU member state in April 2012. Moreover, Compound Danshen Dripping Pills has already been approved to enter the Phase III trials by the US Food and Drug Administration (FDA) and hopefully will be marketed in the U.S. next year. The increasing demand for CPM not only promotes business opportunities with tremendous financial profit but also drives fraudulent companies to adulterate or even substitute the labeled medicinal materials with cheaper plants or animals which share a close resemblance in morphology, chemical composition or clinical usage. These kind of fake drugs are against the theory of Traditional Chinese Medicine and can reduce the efficacy of the drug sharply or even make them poisonous. For instance, in Belgium ${ }^{1}$ during 1990-1992, the toxic herb Aristolochia fangchi was misused as Stephania tetrandra in a diet drug that resulted in over one hundred women's renal failure. So it is of great importance to establish an unequivocal identification system in the quality control of CPM for the safety of patients and benefits of other legal companies.

Traditionally, the authentication of TCM mainly relies on organoleptic parameters ${ }^{2}$ which is an expertdependent technique. But the product identification of highly-processed CPM in the form of tablet, capsule, oral liquid and injection are out of the scope of an experienced taxonomist. In the past few decades, the techniques for chemo-profiling such as TLC, $\mathrm{HPLC}^{3}$ and $\mathrm{GC}^{4}$ have a wide application in the quality assurance of CPM. These methods can complement the limitations of morphological identification to some extent but as the chemotypedriven fingerprints only addressed the detection of certain compounds, so can easily be misleaded. For example in CPM product of ginseng (Panax ginseng C.A. Meyer), some dealers substitute the ginseng root with that of codonopsis (Codonopsis pilosula (Franch.) Nannf.) (Supplementary Figure S7), which is less curative in effect and much cheaper than ginseng. More than that, by adding ginsenosides extract alone rather than the whole ginseng root they can conveniently pass through the chromatographic detection because the ginsenosides was supposed to be the major pharmacologically active components and the chemical marker of ginseng. 
a

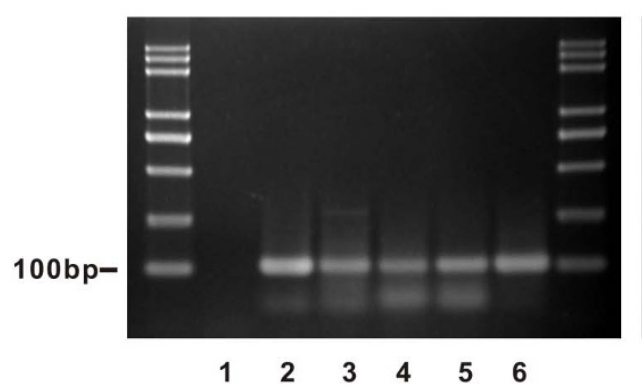

b

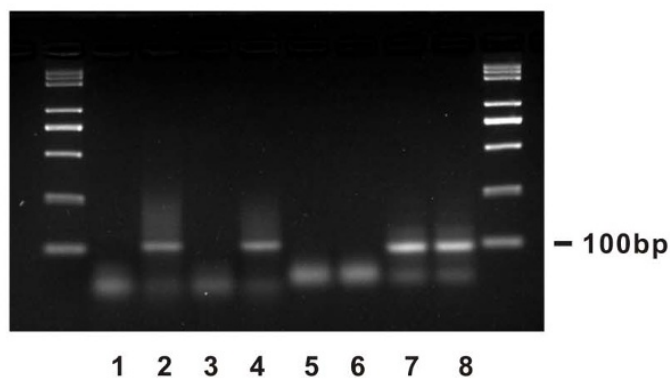

Figure $1 \mid$ (a) Agarose gel electrophoresis of PCR results from ginseng samples. Lane 1-6: negative control (water was used as sample), tablet, pill, oral liquid, injection, positive control (DNA extracted from reference medical material is used as sample). Tablet and pill samples are subjected to one-step simple PCR while oral liquid and injection samples are subjected to nested PCR. (b) Research on the specificity of PCR amplification. In the left four lanes ginseng primers are used. Lane 1-4: negative control (water was used as sample), ginseng oral liquid, codonopsis oral liquid, mixture of ginseng and codonopsis oral liquid. In the right four lanes codonopsis primers are used. Lane 5-8: negative control (water was used as sample), ginseng oral liquid, codonopsis oral liquid, mixture of ginseng and codonopsis oral liquid.

Recently, various studies like random amplified polymorphic DNA(RAPD) ${ }^{6}$, simple sequence repeats(SSRs) ${ }^{7,8}$, restriction fragment length polymorphism(RFLP) $)^{9,10}$ and subtracted diversity $\operatorname{array}(\mathrm{SDA})^{11}$ have been reported to authenticate medicinal herbs. Polymerase chain reaction (PCR) has given scientists a powerful arsenal of molecular tools as it can be used to exponentially amplify trace amounts of DNA. With the help of PCR, it becomes possible to detect DNA of specific natural products in processed drugs and audit the quality of CPM. But among those DNA-based methods of species identification, most of them deal with raw or unprocessed TCM. To our knowledge, this study represents the first application of PCR based technology to the identification of CPM especially the oral liquid and injection ${ }^{12}$ in which the plant is used in the form of extracts and has undergone industrial extraction, filtration and sterilization. There is no doubt about the discriminatory power of DNA among different species. Numerous studies ${ }^{13,14}$ and sequences in Genbank have proved the internal transcribed spacer (ITS) region of nuclear ribosome DNA to be a perfect DNA marker in angiosperm species identification. Because they are much less conserved ${ }^{15}$ than the coding regions and can provide more genetic information, so we focused our study on the polymorphism of the ITS region of each plants.

The ginseng root is one of the best known herbal medicines which has been used as a natural tonic, anti-fatigue and anti-ageing agent traditionally. It has also been reported that ginseng root or CPM product ginseng contained are used to treat diabetes-like conditions ${ }^{16}$ and showed anti-proliferative effect on human prostate cancer cells ${ }^{17}$. There are hundreds of drugs which used ginseng as the mainly therapeutic plant sold in the market of China alone. As mentioned before, ginseng is often adulterated with codonopsis to reduce manufacturing costs. So firstly, we chose ginseng contained CPM and its possible adulterations as our targets to verify our idea.

\section{Results}

Primarily, the classical CTAB (Cetyl trimethylammonium Bromide) method ${ }^{18}$ was used for genomic DNA extraction from solid samples (root powder, tablet and pill) and ethanol precipitation for liquid samples (oral liquid and injection). Extracted DNA was analyzed through agarose gel electrophoresis. Supplementary Figure S1 shows that moderately degraded genomic DNA can be extracted from root powder and some of the tablets in concentrations detectable by agarose gel electrophoresis. While no DNA from pill, oral liquid and injection was observed in agarose gel because most of the DNA could have been removed or degraded during the industrial processing.

While in the pill and oral liquid, the DNA extracted directly by $\mathrm{CTAB}$ or ethanol precipitation without purification is dark brown and viscous (Supplementary Figure S2). Most of those samples couldn't be amplified by PCR. We speculate that the pigments or other substances in the pellet could prohibit the PCR amplification. So the commercial available silica-based spin column DNA purification kit was used. The DNA obtained by column purified shows a normal color and viscosity, which could be amplified by following PCR efficiently. For injection samples magnetic beads kit, ethanol precipitation and the column DNA purification kit were applied to isolate DNA. A similar amplification yield was observed with the DNA extracted by all these methods (Supplementary Figure S3 and Figure S4). But considering magnetic beads kit is costly and ethanol precipitation requires large volume high-speed centrifugation, we prefer column DNA purification kit to concentrate DNA in oral liquid and injection samples.

Extracted DNA from all the samples was subjected to PCR amplification with specific primers for ITS regions. The successful PCR amplification of different kinds of CPM samples which contain ginseng root as starting materials was evidenced by the specific and clear EtBr-stained bands in agarose gel electrophoresis (Figure 1a). 111 bp specific amplification bands were observed only in the positive control, tablet and pill samples (Figure 1a lane 2 and 3) but no amplification was observed in oral liquid and injection samples (data not shown). Considering the low yield of DNA in oral liquid and injection samples, nested PCR was used to improve the efficacy of amplification (Figure 1a lane 4,5 and Supplementary Figure S3). It should be noted that all of the samples were composed of several kinds of medicinal plants or animals rather than ginseng alone. Selected ginseng containing pills "Wu Ji Bai Feng Wan" is a famous and effective gynecological medicine which consists of 20 kinds of medicinal materials including plants and animals (Lane 3, Figure 1a). The specificity of PCR products were further identified by molecular cloning, DNA sequencing and alignment with the already known sequence in genbank and it was found 100\% (98.9\% codonopsis samples) same as the reported sequence.

To check the general applicability of DNA based detection of medical materials in CPM. Different types of CPM products containing Codonopsis pilosula (Franch.) Nannf have been investigated with similar DNA extraction method and specific PCR amplification. All the samples including tablet, pill and oral liquid gave the same desired PCR products based on the gel analysis (Supplementary Figure S5). Those PCR products have been further identified with molecular clone, DNA sequencing too. The cross test of oral liquid CPM samples which contain different materials (gensing, codonopsis or both) was carried out by using the separate PCR detections for gensing and codonopsis to verify the specificity of the PCR based assay (Figure 1b). The successful amplification happened in the orthogonal 
a

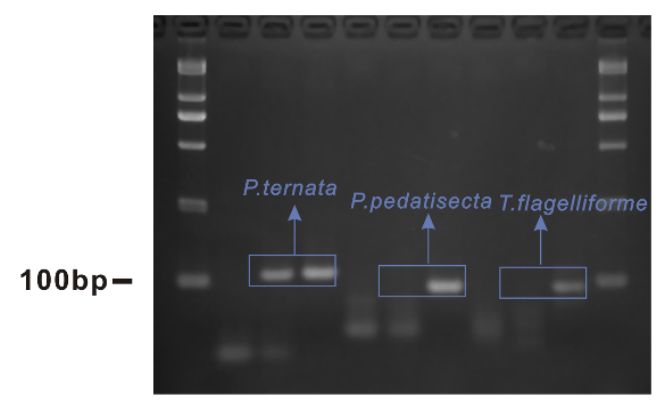

$\begin{array}{lllllllll}1 & 2 & 3 & 4 & 5 & 6 & 7 & 8 & 9\end{array}$ b

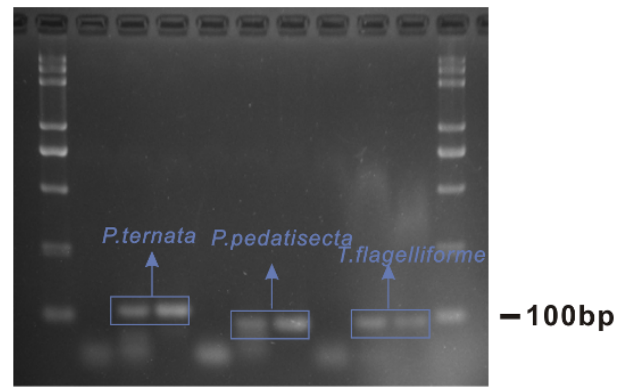

$\begin{array}{lllllllll}1 & 2 & 3 & 4 & 5 & 6 & 7 & 8 & 9\end{array}$

Figure $2 \mid$ Agarose gel electrophoresis of PCR results from sample a and b. Lane 1-3: isolation negative control (water is used as sample when extracted DNA), sample, positive control (DNA extracted from P. ternata is used as template), 4-6: isolation negative control (water is used as sample when extracted DNA), sample, positive control (DNA extracted from P. pedatisecta is used as template), 7-9: isolation negative control (water is used as sample when extracted DNA), sample, positive control (DNA extracted from T. flagelliforme is used as template).

PCR reactions where the specific PCR primers were matching the medical materials (Lane 2 and 7, Figure 1b). The arbitrary mixture of two different oral liquids containing gensing and codonopsis resulted in positive PCR amplification for both gensing and codonopsis detections (Lane 4 and 8, Figure $1 \mathrm{~b}$ ). Those results indicate the possible application of PCR based assay in the detection of the adulteration in CPM.

Huoxiangzhengqi water is one of the best selling oral liquid in China especially in summer, because it can effectively help relieve the discomfort caused by the hot weather. It consists of ten medicinal materials, but among these materials Banxia (Pinellia ternata
(Thunb.) Breit.) rhizoma is the most expensive herbal materials. People have suspected that there could be adulteration in some product for years because the selling price of some manufacturers was less than the cost according to the price of the medicinal materials in the market. The possible adulterations could be the rhizomes of Zhangye banxia (Pinellia pedatisecta Schott) and Shui banxia (Typhonium flagelliforme (lodd.) Blume.). They are ten times cheaper than the Banxia and are highly similar in morphology with each other (Supplementary Figure S7). To prove the PCR could be applied in the detection of aldulteration in CPM. We prepared two kinds of Huoxiangzhegnqi water as the description of Chinese Pharmacopoeia. In

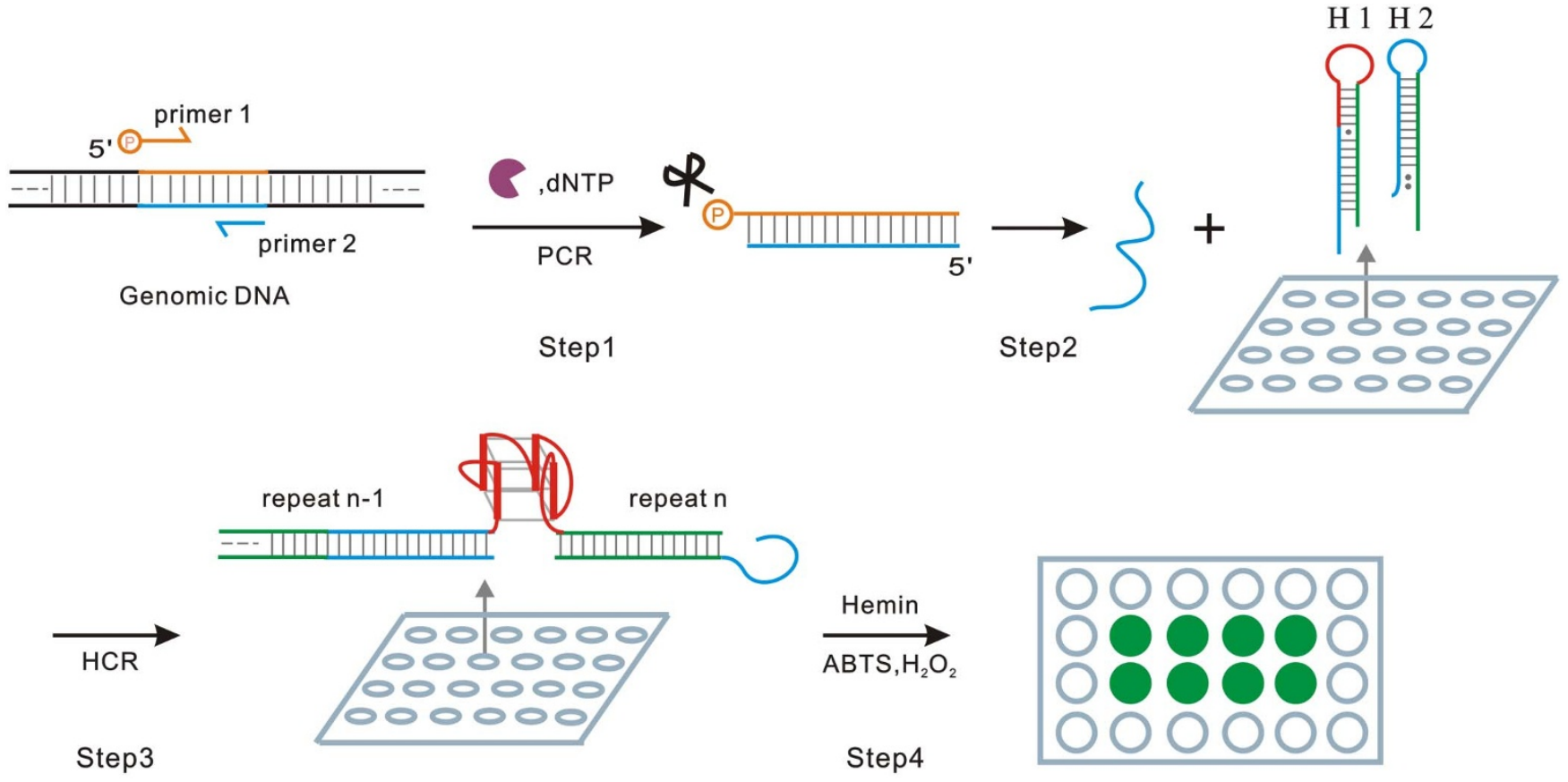

$$
\text { P = phosphate } \quad R=\text { Taq DNA polymerase } \quad R=\text { Lambda Exonuclease }
$$

Figure $3 \mid$ The principle of the chip-basd detection strategy. Step 1: a 5' -phosphorylated primer was used in PCR to get duplex product with all antisense sequences containing phosphate groups at $5^{\prime}$ ends. Step 2: the 5' -phosphorylated stand of duplex DNA was selectively digested by Lambda Exonuclease. Step 3: the ssDNA initiates the two probes open and polymerize to DNA polymers bearing a lot of G-quadruplexes. Step 4: the G-quadruplex bind to hemin and catalyze the oxidization of ABTS to a green product in the presence of $\mathrm{H}_{2} \mathrm{O}_{2}$. Sequences with same color are the same or complementary to each other. 


\section{a}
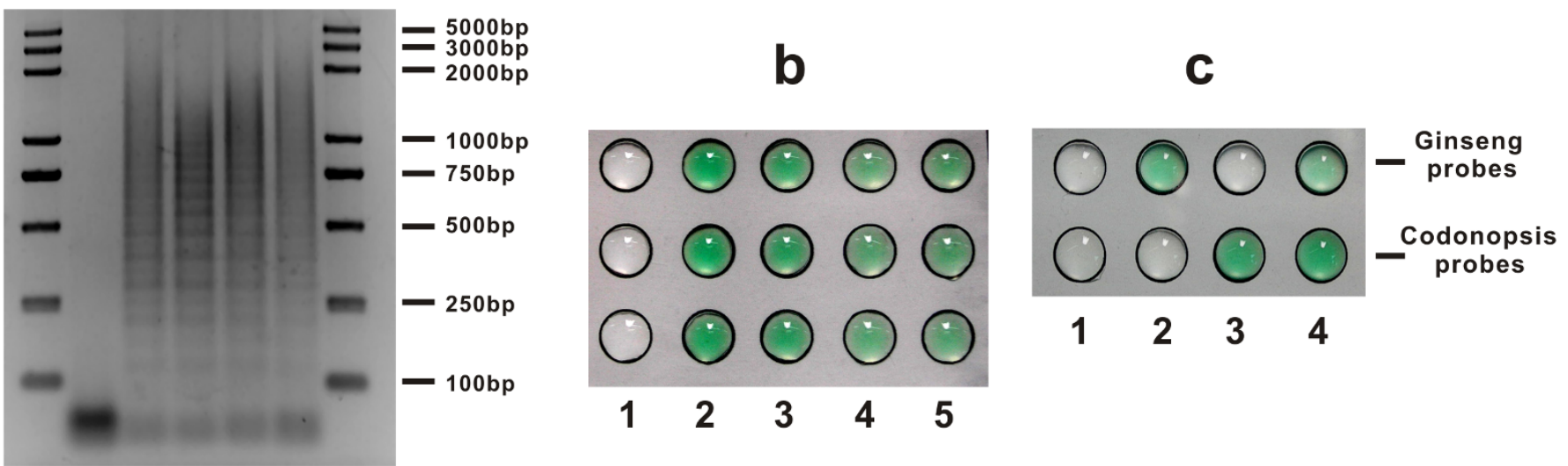

$\begin{array}{lllll}1 & 2 & 3 & 4 & 5\end{array}$

Figure $4 \mid$ (a) Agarose gel electrophoresis of G-quadruplex integrated hybridization chain reactions (GQ-HCR) which were initiate by the digested PCR product from different kinds of ginseng CPM samples. Lane 1-5: negative control (water is used as sample), tablet, pill, oral liquid, injection. (b) Research on the reproducibility of color reaction: the ginseng DNA samples were subjected to three parallel detections (the samples on the same column are the same kind of CPM). All the circles on the chip were pre-printed with special probes for gensing. From 1-5: digested PCR products from negative control (water is used as sample), tablet, pill, oral liquid, injection samples. (c) Research on the specificity of chip-based detection: the two lines were pre-printed with ginseng probes and Codonopsis probes respectively. From 1-4: digested PCR products from negative control (water is used as sample), ginseng oral liquid, Codonopsis oral liquid, mixture of ginseng and Codonopsis oral liquid were added.

sample a, only $P$. ternata was used. While in sample b, $P$. ternata was adulterated with $P$. pedatisecta and $T$. flagelliforme at the ratio of $1: 1: 1$. Specific primers of $P$. ternata, $P$. pedatisecta and $T$. flagelliforme were designed on the basis of the ITS regions. DNA of the two samples were extracted and amplified with the corresponding specific primers. Only the PCR amplification product for $P$. ternata was detected in sample a (Figure 2a) comparing to the successful amplifications for all three materials in sample b (Figure $2 b$ ). As our expectation, the adulterated $P$. pedatisecta and T. flagelliforme in the Huoxiangzhengqi water can be easily detected based on the agarose gel electrophoresis assay of PCR products. Three commercial available Huoxiangzhengqi water products from different companies have been analyzed with the same method. Two of them were found the adulteration with $P$. pedatisecta and T. flagelliforme (data doesn't show to protect the manufactures' identities).

As agarose gel electrophoresis requires a labour-intensive work, we developed a chip-based colorimetric detection approach to distinguish the PCR products of ginseng CPM from its possible adulterants conveniently by taking advantage of a GQ-HCR reaction which is also developed by our group ${ }^{19}$. Figure 3 shows the principle of the detection strategy. One of the PCR primers was 5 ' -phosphorylated to obtain the duplex products in which all antisense sequences of target DNA would contain phosphate groups at the $5^{\prime}$-ends after PCR amplification. Lambda exonuclease $\mathrm{e}^{20}$ is a highly processive $5^{\prime}-3^{\prime}$ exodeoxyribonuclease that can selectively digest the $5^{\prime}$-phosphorylated stand of duplex DNA. After digestion of the undesired strand, the PCR product becomes single stranded which could trigger the following G-quadruplex ${ }^{21,22}$ integrated hybridization chain reaction (GQ-HCR $)^{23,24}$. Two hairpin probes H1 and H2 of GQ-HCR amplification has been printed on a plastic sheet in advance. The ssDNA obtained with Lambda exonuclease digestion was pipetted on the sheet to initiate the two probes open successively to obtain DNA polymers bearing a lot of G-quadruplexes. The G-quadruplex exhibited peroxidase-like activity in the presence of hemin, which could catalyze the oxidization ABTS (2,2' -azino-bis(3- ethylbenzthiazoline-6-sulphonic acid)) with aid of $\mathrm{H}_{2} \mathrm{O}_{2}$ to obtain green product.

The digested PCR products from ginseng CPM were added to initiate the two specific hairpins probes to polymerize. It is showed in the agarose gel (Figure 4a) that the hairpin monomers have assembled to DNA polymers with different molecular weight and the efficiency of the polymerization is proportional to the initial concentration of PCR products. As shown in the picture, there is more substrate left in injection compared to the tablet since it has less amplification product in injection sample (Line 2-5, Figure 4a).

DNA from different ginseng containing CMP was extracted and subjected to following detection in three parallel experiments. All kinds of CMP samples gave positive response (the bright green color in ginseng containing drugs samples, column 2-5, Figure 4b) comparing the negligible background of negative control (water is used as template in PCR amplification) (column 1, Figure 4b). There is no obvious difference between the colorimetric results from the same kind of drug, which indicate the good reproducibility of this method. The color density is also consistent with the GQ-HCR results (Figure 4a): since the tablet and pill have yielded more HCR product, so intensity of their color is somehow greener on the visual chip compared to oral liquid and injection.

The visual-chip based assay should be ideal method to detection of aldulteration in CPM. As shown in Figure 4c, the first row was printed with ginseng probes and the second was printed with Codonopsis probes respectively. Lambda exonuclease Digested PCR products from ginseng oral liquid, Codonopsis oral liquid and the mixture of ginseng with Codonopsis oral liquid were pipetted onto the corresponding circles on the chip in both rows. Green color on the chip indicated that Ginseng and Codonopsis could be detected successfully with their respective probes on the chip with negligible background in negative control (column 2 and 3, Figure 4c). Additionally, Ginseng and Codonopsis could be detected simultaneously in artificially mixed sample (column 4 , Figure $4 \mathrm{c}$ ), which revealed the aldulteration in the detected sample. What's more, the visual results can also be detected by the spectrophotometer or other similar instruments, more details please see Supplementary Figure S7.

\section{Discussion}

Here we report a new approach for the authentication of CPM especially the oral liquid and injection samples by applying Molecular Biotechnological tools. Described procedure is sensitive enough to detect trace amounts of DNA in CPM which has undergone intense industrial processing. Further it has been developed to an easy to use and cost-effective visual-chip based assay that needs no expensive sequence or Gene chip scanner. With a high reproducibility and 
specificity, similar approach can also be rationalized to authenticate other medicinal plants or animals in CPM. Therefore, with TCM globalization, a potential increase in the export of authenticated CPM as drugs or as botanical dietary supplements for health enhancement will be possible all over the world. In this regard proposed method could be used to minimize health risk of adulterants, protect the commercial interests of quality suppliers and may finally become a powerful tool in the quality assurance of CPM not only in China but also around the world.

\section{Methods}

Drugs used in this study. Panax Ginseng drugs (tablet, pill, oral liquid and injection) and Codonopsis pilosula drugs (tablet, pill, oral liquid) were purchased from local pharmacy in Chengdu, People's Republic of China. To protect the manufacturer's identities, sample sources are described as its preparation name. Root powder of Panax ginseng C. A. Meyer, Codonopsis pilosula (Franch.) Nannf and Pinellia ternata (Thunb.) Breit were purchased from National institute for food and drug control as positive control.

DNA extraction. The classic CTAB (Cetyl trimethylammonium Bromide) method is used in the DNA extraction of the root powder with a slight modification. $100 \mathrm{mg}$ material was suspended in $750 \mu \mathrm{l}$ of CTAB buffer ( $2 \%$ CTAB; $100 \mathrm{mM}$ Tris- $\mathrm{HCl}, \mathrm{pH}$ $8: 0 ; 20 \mathrm{mM} \mathrm{EDTA} ; 2.5 \mathrm{M} \mathrm{NaCl}$ ) and then incubated at $65^{\circ} \mathrm{C}$ for $2 \mathrm{~h}$ with occasional shaking. The lysate was extracted with $600 \mu \mathrm{l}$ of chlorophorm:isoamyl alcohol $(24: 1)$. DNA was precipitated with equal volume of $100 \%$ isopropanol (30 $\mathrm{min}$ at $-20^{\circ} \mathrm{C}$, followed by centrifugation at $10,000 \mathrm{~g}$ for $15 \mathrm{~min}$ ). DNA pellet was washed twice with cold $70 \%$ ethanol, vacuum dried and resuspended in $40 \mu \mathrm{l}$ of TE buffer $(10 \mathrm{mM} \text { Tris- } \mathrm{HCl}, \mathrm{pH} 8: 0 ; 1 \mathrm{mM} \text { EDTA })^{25}$. As the tablets and pills contain some pharmaceutical excipients, column DNA purification kit was used as described in the manufacturer's instructions after isopropanol precipitation. This kit was also used to concentrate and purify DNA in oral liquid and injection.

PCR amplification. Simple PCR. PCR was performed in a $50 \mu \mathrm{l}$ reaction mixture containing 1-2 $\mu \mathrm{l}$ of DNA template from the root powder, tablets or pills, $10 \times \mathrm{Taq}$ buffer $\left(200 \mathrm{mM}\right.$ Tris- $\mathrm{HCl}, \mathrm{pH} 8.4,200 \mathrm{mM} \mathrm{KCl}, 100 \mathrm{mM}\left(\mathrm{NH}_{4}\right)_{2} \mathrm{SO}_{4}, 20 \mathrm{mM}$ $\left.\mathrm{MgSO}_{4}\right), 0.2 \mathrm{mM}$ dNTPs, $1 \mu \mathrm{M}$ of each primer and 5 units of EasyTaq polymerase. Initial template denaturation was done at $95^{\circ} \mathrm{C}$ for $3 \mathrm{~min}$, followed by 35 cycles of $94^{\circ} \mathrm{C}$ for $30 \mathrm{~s}, 55^{\circ} \mathrm{C}\left(50^{\circ} \mathrm{C}\right.$ for Codonopsis samples) for $30 \mathrm{~s} \& 72^{\circ} \mathrm{C}$ for $30 \mathrm{~s}$ with final extension of $72^{\circ} \mathrm{C}$ for $5 \mathrm{~min}$.

Nested PCR. $1^{\text {st }}$ round PCR was carried out in a $50 \mu \mathrm{l}$ reaction mixture containing 5$10 \mu \mathrm{l}$ of DNA, $10 \times$ Taq buffer $(200 \mathrm{mM}$ Tris- $\mathrm{HCl}$, pH 8.4, $200 \mathrm{mM} \mathrm{KCl}, 100 \mathrm{mM}$ $\left.\left.\left(\mathrm{NH}_{4}\right)_{2} \mathrm{SO}_{4}, 20 \mathrm{mM} \mathrm{MgSO}\right)_{4}\right), 0.2 \mathrm{mM}$ dNTPs, $0.25 \mu \mathrm{M}$ of each external primers and 5 units of EasyTaq polymerase. Initial template denaturation was done at $95^{\circ} \mathrm{C}$ for $3 \mathrm{~min}$, followed by 30 cycles of $94^{\circ} \mathrm{C}$ for $30 \mathrm{~s}, 60^{\circ} \mathrm{C}\left(54^{\circ} \mathrm{C}\right.$ for Codonopsis samples) for $30 \mathrm{~s} \& 72^{\circ} \mathrm{C}$ for $30 \mathrm{~s}$ with final extension of $72^{\circ} \mathrm{C}$ for $5 \mathrm{~min}$.

$1 \mu \mathrm{l}$ PCR product of the first round PCR was used as template for $2^{\text {nd }}$ round PCR and other details of the second round PCR was the same as described for simple PCR.

GQ-HCR and color reaction. The PCR product was incubated with 10 units of Lambda exonuclease enzyme at $37^{\circ} \mathrm{C}$ for $1 \mathrm{~h}$ to digest one strand of double stranded DNA. The GQ-HCR was carried out in a $10 \mu \mathrm{l}$ mixture containing $8 \mu \mathrm{l}$ digested products, $0.5 \mu \mathrm{M}$ probes, $400 \mathrm{mM} \mathrm{NaCl}$. For visual chip, $8 \mu \mathrm{l}$ of digested PCR products were pipetted on a plastic film which was pre-printed 5 pmol of DNA probes. The film was incubated at $37^{\circ} \mathrm{C}$ for $1 \mathrm{~h}$ and subjected to detection reagents $\left(1.5 \mu \mathrm{l}\right.$ of $60 \mathrm{mM}$ ABTS, $0.5 \mu \mathrm{l}$ of $60 \mu \mathrm{M}$ Hemin \& $0.5 \mu \mathrm{l}$ of $60 \mathrm{mM} \mathrm{H}_{2} \mathrm{O}_{2}$ ) afterwards, color change was observed by naked eyes on the visual DNA chip.

1. Vanherweghem, J. L. Misuse of herbal remedies: The case of an outbreak of terminal renal failure in Belgium (Chinese herbs nephropathy). Journal of Alternative and Complementary Medicine 4, 9-13 (1998).

2. Joshi, K., Chavan, P., Warude, D. \& Patwardhan, B. Molecular markers in herbal drug technology. Curr. Sci. 87, 159-165 (2004).

3. Li, W. K. \& Fitzloff, J. F. HPLC with evaporative light scattering detection as a tool to distinguish Asian ginseng (Panax ginseng) and North American ginseng (Panax quinquefolius). J. Liq. Chromatogr. Rel. Technol. 25, 17-27 (2002).

4. Shellie, R. A., Marriott, P. J. \& Huie, C. W. Comprehensive two-dimensional gas chromatography $(\mathrm{GC} \times \mathrm{GC})$ and GC $\times$ GC-quadrupole $\mathrm{MS}$ analysis of Asian and American ginseng. J. Sep. Sci. 26, 1185-1192 (2003).

5. Dharmananda, S. The Nature of Ginseng: Traditional Use, Modern Research, and the Question of Dosage. Herbal Gram 34-51 (2002).
6. Xu, H. et al. A preliminary RAPD-PCR analysis of Cimicifuga species and other botanicals used for women's health. Phytomedicine 9, 757-762 (2002).

7. Kim, J. et al. Identification of new microsatellite markers in Panax ginseng. Mol Cells 24, 60-68 (2007).

8. Kim, J. \& Chung, K. W. Isolation of new Microsatellite-containing sequences in Acanthopanax senticosus. J. Plant Biol. 50, 557-561 (2007).

9. Del Serrone, P. et al. Molecular identification of Panax ginseng C.A. Meyer in ginseng commercial products. Nat. Prod. Commun. 1, 1137-1140 (2006).

10. Ngan, F., Shaw, P., But, P. \& Wang, J. Molecular authentication of Panax species. Phytochemistry 50, 787-791 (1999).

11. Niu, L. H. et al. Detection of Panax quinquefolius in Panax ginseng using 'subtracted diversity array'. J. Sci. Food Agric. 91, 1310-1315 (2011).

12. Del Serrone, P., Attorri, L. \& Palazzino, G. Easy DNA extraction for rapid detection of Panax ginseng C. A. Meyer in commercial ginseng products. Nat. Prod. Res. 21, 1099-1103 (2007).

13. Chiou, S. J., Yen, J. H., Fang, C. L., Chen, H. L. \& Lin, T. Y. Authentication of medicinal herbs using PCR-Amplified ITS2 with specific primers. Planta Med. 73, 1421-1426 (2007).

14. Chen, S. L. et al. Validation of the ITS2 Region as a Novel DNA Barcode for Identifying Medicinal Plant Species. Plos One 5, e8613 (2010).

15. LeRoy, A., Potter, E., Woo, H. H., Heber, D. \& Hirsch, A. M. Characterization and identification of alfalfa and red clover dietary supplements using a PCR-based method. J. Agric. Food. Chem. 50, 5063-5069 (2002).

16. Xie, J. T., Mehendale, S. \& Yuan, C. S. Ginseng and diabetes. Am. J. Chin. Med. 33, 397-404 (2005).

17. Liu, W. K., Xu, S. X. \& Che, C. T. Anti-proliferative effect of ginseng saponins on human prostate cancer cell line. Life Sci. 67, 1297-1306 (2000).

18. Porebski, S., Bailey, L. G. \& Baum, B. R. Modification of a CTAB DNA extraction protocol for plants containing high polysaccharide and polyphenol components. Plant Molecular Biology Reporter 15, 8-15 (1997).

19. Dong, J., Cui, X., Deng, Y. \& Tang, Z. Amplified detection of nucleic acid by Gquadruplex based hybridization chain reaction. Biosens. Bioelectron. 38, 258-263 (2012).

20. Higuchi, R. G. \& Ochman, H. Production of single-stranded-DNA templates by Exonuclease digestion following the polymerase chain-reaction. Nucleic Acids Res. 17, 5865-5865 (1989).

21. Travascio, P., Li, Y. F. \& Sen, D. DNA-enhanced peroxidase activity of a DNA aptamer-hemin complex. Chem. Biol. 5, 505-517 (1998).

22. Du, F. \& Tang, Z. Colorimetric Detection of PCR Product with DNAzymes Induced by 5 '-Nuclease Activity of DNA Polymerases. ChemBioChem 12, 43-46 (2011).

23. Pierce, N. A., Yin, P., Choi, H. M. T. \& Calvert, C. R. Programming biomolecular self-assembly pathways. Nature 451, 318-U314 (2008).

24. Dirks, R. M. \& Pierce, N. A. Triggered amplification by hybridization chain reaction. Proc. Natl. Acad. Sci. USA 101, 15275-15278 (2004).

25. Bashalkhanov, S. \& Rajora, O. P. Protocol: A high-throughput DNA extraction system suitable for conifers. Plant Methods 4, 20 (2008).

\section{Acknowledgments}

This study was supported by Chinese Academy of Science (Hundreds of Talents Program), National Sciences Foundation of China (Grant No. 21172215 and 21102140) and Innovation Program of the Chinese Academy of Sciences (Grant No. KSCX2-EW-J-22) and Open Research Fund of State Key Laboratory Breeding Base of Systematic Research, Development and Utilization of Chinese Medicine Resource.

\section{Author contributions}

X.C., Y.D. and Z.T. conceived and designed the research. R.C., X.C., W.W. and Y.Z. performed experiments. R.C., A.Y. and Z.T. analyzed the data and wrote the manuscript

\section{Additional information}

Supplementary information accompanies this paper at http://www.nature.com/ scientificreports

Competing financial interests: The authors declare no competing financial interests

License: This work is licensed under a Creative Commons

Attribution-NonCommercial-NoDerivs 3.0 Unported License. To view a copy of this license, visit http://creativecommons.org/licenses/by-nc-nd/3.0/

How to cite this article: Chen, R. et al. DNA based identification of medicinal materials in Chinese patent medicines. Sci. Rep. 2, 958; DOI:10.1038/srep00958 (2012). 